\title{
In vitro Propagation of Critically Endangered Endemic Rhaponticoides mykalea (Hub.-Mor.) by Axillary Shoot Proliferation
}

\author{
Yelda Emek and Bengi Erdag \\ Additional information is available at the end of the chapter
}

http://dx.doi.org/10.5772/55599

\section{Introduction}

Turkey is one of the richest countries in variability of flora. It has nearly 9000 plant species about 3000 of which are endemic [1]. Asteraceae, is represented by 50 species in Turkey with an endemism of nearly 54\% [2]. Rhaponticoides mykalea (Hub.-Mor.) M.V. Agab. \& Greuter which belongs to the Asteraceae family, falls within the CR (Critically Endangered) category in the Red Data Book of Turkey [1]. While R. mykalea (Hub.-Mor.) was classified under the section Centaurea as Centaurea mykalea (Hub.-Mor.) before now. Today it has been separated from the section Centaurea [3]. It spreads very scarce in Kuşadası (Aydın), Muğla and Isparta, and faces with the danger of extinction. $R$. mykalea that has very limited number of individuals is under strong anthropogenic pressure such as the gradually increase in ongoing urbanization due to rapid developments of tourism sector, the conversion of natural habitats into human dominated lands, the over-grazing and collecting capitula of $R$. mykalea by local people for food. The species has already been under the threat of extinction and the situation above will increase the risk of extinction of this species even more [4]. For this reason, local protection measures and global conservation strategies are necessary [5].

Nowadays, the conservation of wild plant genetic resources is very important for preventing a decrease in genetic variability. Conservation of the endemic or threatened plants is carried out using different strategies. In vitro culture is an efficient method for ex situ conservation of plant diversity [6,7], because many endangered species can be quickly propagated and preserved from a minimum of plant material with low impact on wild populations with this technology [8]. In recent years, there has been an increased interest in in vitro techniques that offer powerful tools for germplasm conservation and the mass multiplication of many 
threatened plant species [9]. Especially in vitro propagation of endangered plants can offer considerable benefits for the rapid cultivation of at risk species that have a limited reproductive capacity and exist in threatened habitats [5].

Micropropagation constitutes a powerful tool for $e x$ situ conservation programs of threatened plants, especially for species with very reduced populations or low seed production [6,7]. This technique facilitates the rapid establishment of a large number of stock plants, from a minimum of original plant material, thus imposing minimum impact on the endangered wild populations. Axillary shoot proliferation typically results in average tenfold increase in shoot number per monthly culture passage. In a period of 6 months, it is feasible to obtain as many as 1000 000 propagulesor plants, starting from a single explant [10].With this technology various endemic and endangered species have been successfully propagated; such as and Centaurea paui [8], Anthemis xylopoda O.Schwarz [11], Centaurea spachii [12], Centaurea zeybekii [13], Centaurea junoniana [14], Astragalus chrysochlorus [15], Centaurium rigualii [16] and Syzygium alternifolium [17].

However, during our literature search, no report concerning in vitro regeneration of R.mykalea by axillary shoot proliferation was found.

The objective of the present study was to establish an efficient in vitro method for the rapid propagation via axillary shoot propagation of R.mykalea, a critically endangared endemic plant species. The shoots that were obtained from in vitro germinated mature embryos were used for axillary shoot proliferation. For that reason, the most appropriate cytokinin type and concentration were determined.

\section{Material and methods}

\subsection{Plant material and explant source}

Capitula of Rhaponticoides mykalea were collected from a wild population in Aydin-Turkey (Samsun mountain, localities: N $37^{\circ} 47.01^{\text {“ }}$; E $027^{\circ}$ 19.16 “) during summer period (July and August -2008) before seed dormancy period (Figure 1).

R. mykalea has been propagated from seed in the past [18]. However, researchers have explained that the seed is not suitable explant for in vitro propagation of $R$. mykalea due to strong seed dormancy and low germination frequency even after dormancy period. Therefore, embryos isolated from achenes which have not yet crossed dormancy periods were used as initial explant.

The achenes isolated from capitula were sterilised, and mature zygotic embryos that were dissected out from achene were used as initial explant. Mature zygotic embryos were dissected out from achenes and cultured on Murashige and Skoog (MS) [19] basal medium for germination. The shoots that were obtained from in vitro germinated mature embryos were used for axillary shoot proliferation. 


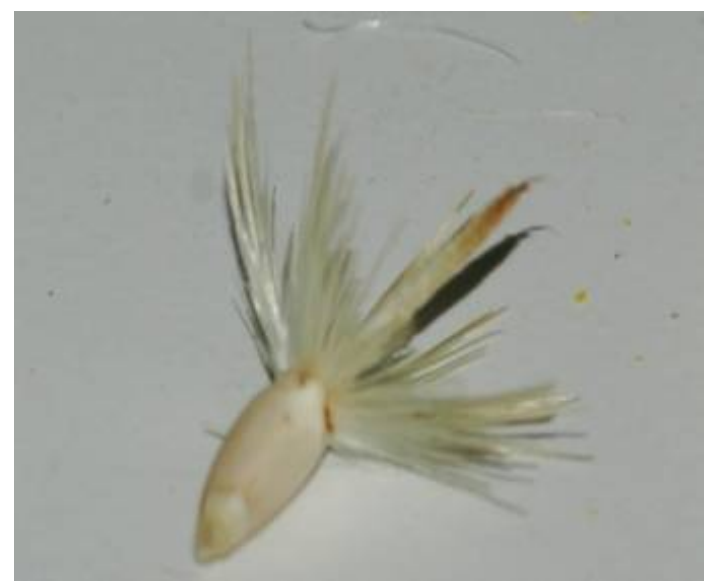

Figure 1. Achene containing mature embryo (before dormancy).

\subsection{Achene viability}

Achene viability was subjected to tetrazolium test.Tetrazolium test is based on reduction of colourless solution 2,3,5-tripheniltetrazolim chloride or bromide into insoluble 2,3,5- triphenilformazan red in colour. This solution acts as an indicator for detection of reduction processes that take place in living parts of the seed. Inside the seed, tetrazolium intakes hydrogen from dehydrogenase. By hidrogenization of tetrazolium a red, stable substance called formazan, which dyes living parts of the seed, is formed in the living cells.Tissue of many plant species must be removed to introduce the dye into the tissue. Tissue removal can be done by pilling the seed coat off, punching, and longitudinal or cross-cutting of unessential seed parts. Prepared seed is submerged into 0,5-1\% tetrazolium solution. Seed must be completely covered with solution, and not exposed to direct light. After the time needed for dyeing expires (it depends on plant species) the estimation of dyeing is approached. All tissue (necessary for normal seedling development) of a viable seed should be dyed. Except completely dyed, viable seeds, and completely undyed, unviable seeds, a partly dyed seeds may also be found. Depending on the species, small undyed spots of some parts of these tissues may be accepted. Location, size of undyed areas, and sometimes intensity of dyeing, determine whether some seed is considered as viable or not [20].

To determine achene viability of $R$. mykalea, longitudinally-halved seeds were treated in tetrazolium solution (TTC, $1 \%$ ) for $2 \mathrm{~h}$ at room temperature. After that time, red staining embryos were evaluated as alive.

\subsection{Seed sterilisation, media preparation and culture conditions}

In order to determine proper sterilisation procedure, achenes isolated from capitula were washed thoroughly under running tap water for 30 mins. Subsequently at various times, achenes were put in $70 \%(\mathrm{w} / \mathrm{v})$ ethanol and $4.5 \%(\mathrm{w} / \mathrm{v})$ sodium hypochlorite containing 2 drops 
of wetting agent (Tween-80); afterwards, the achenes were rinsed three times (5 mins each) with sterile distilled water in a laminar flow hood. After sterilisation, zygotic embryos were isolated from achenes and cultured on PDA (Potato Dextrose Agar) to determine early contamination. PDA cultures were maintained at $24 \pm 2{ }^{\circ} \mathrm{C}$ for 3 days. At the end of this period, observations were made in order to determine the appropriate sterilisation time.

All the experiments were maintained on semi-solid basal medium supplemented with or without various concentration of plant growth regulators. Basal medium contained Murashige and Skoog (MS) [19] mineral salts, $100 \mathrm{mgl}^{-1}$ myo-inositol, $2 \mathrm{mgl}^{-1}$ glycine, $0.5 \mathrm{mgl}^{-1}$ nicotinic acid, $0.5 \mathrm{mgl}^{-1}$ pyridoxine- $\mathrm{HCl}, 0.1 \mathrm{mgl}^{-1}$ thiamine-HCL, 3\% (w/v) sucrose, $8 \mathrm{gl}^{-1}$ agar (Agaragar), various concentration of plant growth regulators ${ }^{1} \mathrm{~N}^{6}$ - Benzyladenine (BA) and Kinetin (KIN), indole-3-butyric acid (IBA), indole-3-acetic acid (IAA) or naphthalene acetic acid (NAA) were used in experiments depending on experimental objectives.

The $\mathrm{pH}$ of media was adjusted to 5.8 with $1 \mathrm{M} \mathrm{NaOH}$ or $\mathrm{HCl}$ prior to autoclaving at $105 \mathrm{kPa}$ and $121^{\circ} \mathrm{C}$ for $15 \mathrm{~min}$. Culture vessels were $190 \mathrm{ml}$ glass jars containing $30 \mathrm{ml}$ of medium.

\subsection{Axillary shoot proliferation}

Mature embryos that were isolated from achenes were cultured on MS basal medium to obtain sterile seedlings (unpublished data). After eight weeks, seedlings $(\sim 2-3 \mathrm{~cm})$, were separated from primary roots and transferred to MS medium containing different concentrations of BA or $\operatorname{KIN}\left(0.1,0.5,1.0\right.$ and $\left.2.0 \mathrm{mgl}^{-1}\right)$ for axillary shoot propagation. A control treatment without cytokinins was also included. At the end of the 3 subculture, the number of shoots per explant and average shoot length was evaluated for each cytokinin type and concentration.

Axillary shoot proliferation experiments were conducted with 15 replications consisting of one explant per jar and were repeated three times. Cultures were incubated at $24 \pm 2{ }^{\circ} \mathrm{C}$ under a light regime of $16 \mathrm{~h}$ photoperiod by cool-white fluorescent lamps. The cultures were subcultured to fresh medium of the same composition at an interval of 4 weeks.

\subsection{Shoot rooting and acclimatization of plantlets}

After three subcultures, elongated shoots $(\sim 4 \mathrm{~cm})$ were excised stock cultures and transferred to MS and half strength MS medium ( $1 / 2 \mathrm{MS})$ with or without different concentrations $(0.5,1.0$, 2.0 and $5.0 \mathrm{mgl}^{-1}$ ) of auxins (IBA, IAA or NAA) for rooting. The results of rooting experiments were expressed in percentage after 6 weeks of culture initiation.

Rooting experiments were conducted with 15 replications consisting of one explant per jar and were repeated three times. Cultures were incubated at $24 \pm 2{ }^{\circ} \mathrm{C}$ under a light regime of $16 \mathrm{~h}$ photoperiod by cool-white fluorescent lamps. The cultures were subcultured to fresh medium of the same composition at an interval of 4 weeks.

After 8 weeks of rooting in vitro, the plantlets were removed from the culture jars then the agar was carefully washed off the rooted plantlets to minimize pathogen attack. The plantlets were planted into $10 \mathrm{~cm}$ diameter plastic pots containing garden soil and kept in the growth chamber 
under $24 \pm 2^{\circ} \mathrm{C}$ and 16-h light photoperiod. After 4 weeks the plantlets kept at normal laboratory conditions.

\subsection{Statistical analyses}

Means of shoot number per explant, shoot lenght and frequency of rooting were analyzed by one-way analysis of variance (ANOVA, SPSS for Windows v.9., SPSS, USA). Differences were analyzed by analysis of variance and the means compared using Duncan's multiple range test at $\mathrm{p}<0.05$. Data giving in percentages were subjected to $\mathrm{x}^{\prime}=\operatorname{arcsine} \sqrt{ }$ $(\mathrm{x} / 100)$ transformation [21].

\section{Results and discussion}

The viability percentage of achenes was $80 \%$ according to Tetrazolium test. According to our results, the most suitable sterilisation procedure of achenes is as follows: The achenes are washed thoroughly under running tap water for 30 mins. After this process, seeds must be exposed to $70 \%(\mathrm{w} / \mathrm{v})$ ethanol for five mins and then to $4.5 \%(\mathrm{w} / \mathrm{v})$ sodium hypochlorite containing 2 drops wetting agent (Tween-80) for eight mins. Finally, seeds are rinsed three times with sterilised distilled water (5 mins each). Sterile cultures are than obtained in high proportion (100\%).

Four-week-old sterile seedlings obtained from mature zygotic embryos were used as explant for axillary shoot proliferation experiments. At the end of the experiments, the most appropriate cytokinin type and concentration were determined (Figure 2). Axillary shoot propagation of R. mykalea was obtained in all media without or with cytokinin. Cytokinins are generally recognized as critical for the production of shoot primordia under in vitro conditions. Both cytokinins induced healthy shoots in our study. However, it is shown that BA is more effective cytokinin than KIN. The maximum shoot number per explant were obtained in $0.5 \mathrm{mgl}^{-1} \mathrm{BA}$ added MS medium (5.8 shoot/explant) (Figure 2 and 3).

A decrease in the number of shoots were observed at both higher $\left(1\right.$ and $\left.2 \mathrm{mgl}^{-1}\right)$ and lower concentrations of BA $\left(0.1 \mathrm{mgl}^{-1}\right)$. Similar results were also reported for axillary shoot proliferation of Centaurea spachii [12] and Centaurea zeybekii [13]. BA was also reported as an effective cytokinin for other endemic and threatened Centaurea species [14, 16]. However, BA was evaulated as an effective cytokinin for shoot multiplication in many species of Asteraceae; such as Centaurea junoniana [14], Gerbera jamesonii hybrida [22], Centaurium rigualii [16], Syzygium alternifolium [17] and Anthemis xylopoda [11].

MS medium supplemented with $0.1 \mathrm{mgl}^{-1}$ Kinetin (KIN) was determined as the most suitable medium for the maximum shoot length $(7.35 \mathrm{~cm}$ ) (Figure 4). While BA is more effective cytokinin on shoot multiplication, KIN is more effective on shoot lenght. In spite of the increased number of shoots on media containing cytokinin, the shoot length is decreased. A negative correlation between the shoot number and their length has been observed. This kind of negative correlation was reported in Centaurea paui by using inflorescence stalk as explant [8] and C. zeybekii by axillary shoot proliferation [13]. 


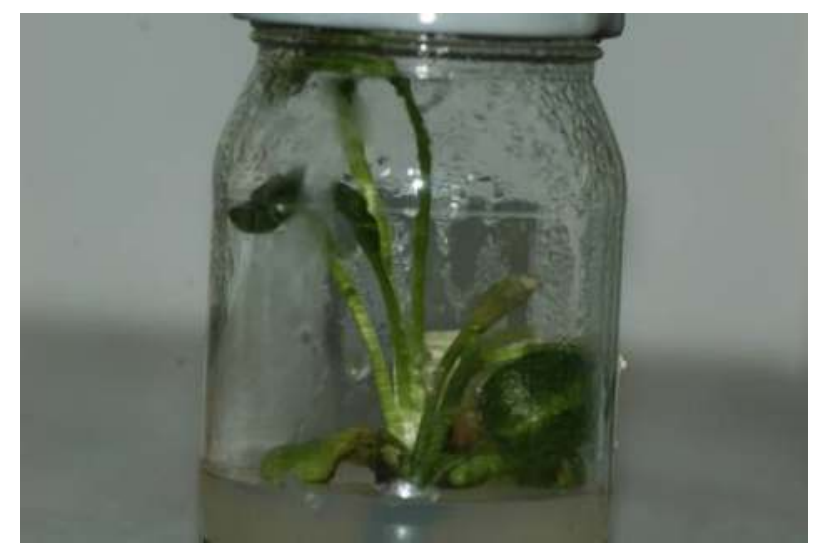

Figure 2. Axillary shoot proliferation on MS medium added $0.5 \mathrm{mgl}^{-1} \mathrm{BA}$.

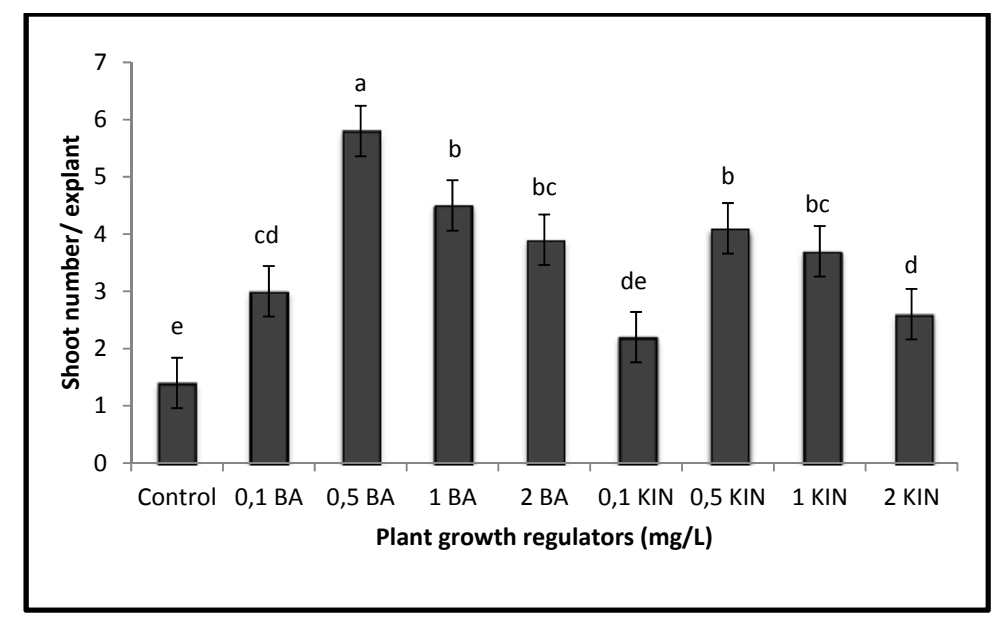

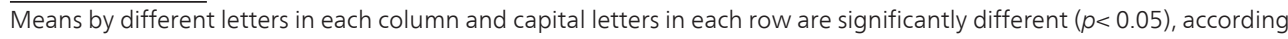
to Duncan Multiple Range Test.

Figure 3. Cytokinin effects on axillary shoot multiplication of R.mykalea.

After three subculturing, solitary shoots excised from multiple shoot cultures were transferred to MS and $1 / 2$ MS media containing IAA, IBA and NAA at various concentrations for rooting. Rhizogenezis was not occured MS and 1/2 MS medium without plant growth regulators. Auxin is necessary for in vitro rooting of R.mykalea axillary shoots. Generally, $1 / 2$ MS medium added auxin is more effective than MS medium added auxin for rooting. The maximum rooting rate was obtained with half-strength MS medium supplemented with $0.5 \mathrm{mgl}^{-1}$ IBA (55\%) (Figure 5 and 6). There are many of reports about IBA is 


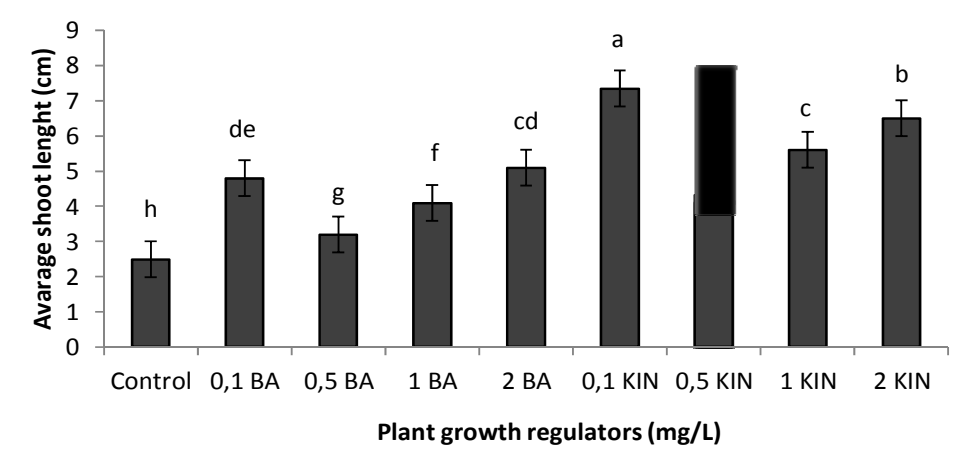

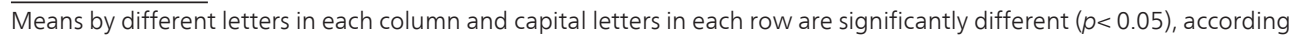
to Duncan Multiple Range Test.

Figure 4. Average shoot lengths of axillary shoots dependent on cytokinin type and concentration.

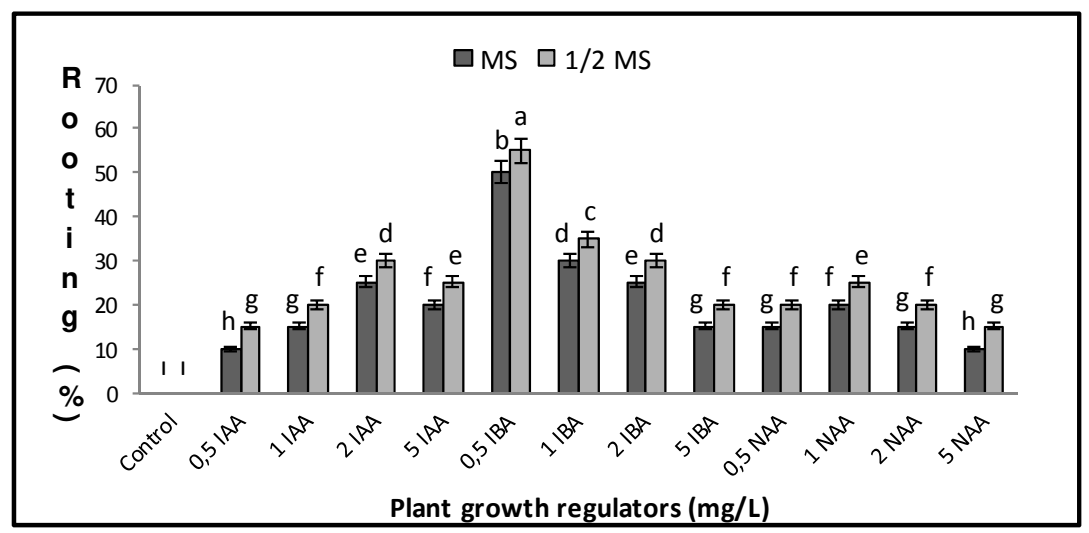

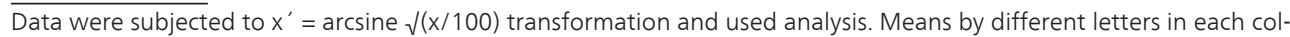
umn and capital letters in each row are significantly different $(p<0.05)$, according to Duncan Multiple Range Test.

Figure 5. Rooting of R.mykalea axillary shoots.

more effective than other auxins on rooting for Asteraceae such as Anthemis xylopoda [11, 23], Centaurea spachii [12], Centaurea ragusina [24], Centaurea zeybekii [25] and Saussurea obvallata [26].

There was a statistically significant difference between MS and $1 / 2$ MS medium on rooting. $1 / 2$ MS medium is more effective than MS medium on rooting in all experiments. Also, there was a statistically significant difference on rooting of $R$. mykalea between auxin type and concentration. 


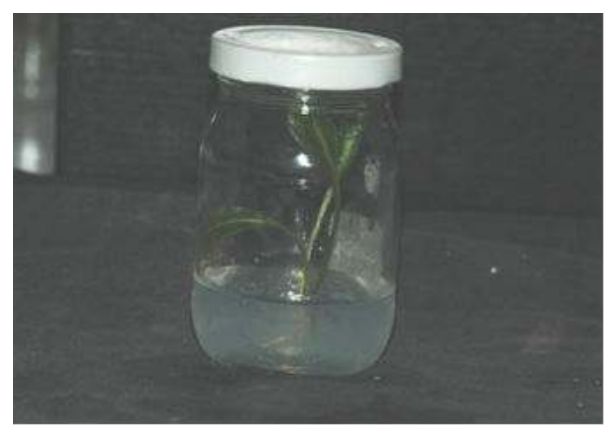

Figure 6. Rooting plantlets on $1 / 2 \mathrm{MS}$ medium added $0.5 \mathrm{mgl}^{-1} \mathrm{IBA}$.

In this study, we described a successful and rapid propagation techniques to regenerate critically endangered R.mykalea the first time by in vitro tissue culture techniques. Mature zygotic embryos isolated from achenes were used as starting material. The shoots that were obtained from in vitro germinated mature embryos were separated from primary roots and used for axillary shoot propagation. The highest axillary shoot number per explant was obtained on MS medium supplemented with $0.5 \mathrm{mgl}^{-1}$ BA (5.8 shoot/explant). MS medium supplemented with $0.1 \mathrm{mgl}^{-1} \mathrm{KIN}$ was determined as the most suitable medium for the maximum shoot length $(7.35 \mathrm{~cm})$. Solitary shoots, removed from stock cultures, were transferred onto half-strength MS ( $1 / 2$ MS) or MS media supplemented with various concentrations of auxins. The maximum rooting rate was obtained with half-strength MS medium supplemented with $0.5 \mathrm{mgl}^{-1} \mathrm{IBA}(55 \%)$. Rooted plantlets were transferred to external environment step by step.

The plantlets with well devoloped root were transferred to ex vitro conditions (Figure 7). Percentage of survival of shoots was approximately $60 \%$. The appearance and growth of these plantlet were also normal.

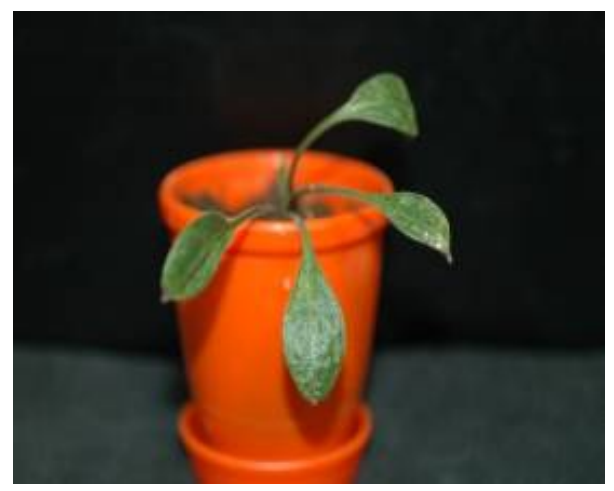

Figure 7. Acclimatized plantlets. 


\section{Conclusions}

In conclusion, the present work presents a simple and successful procedure for the in vitro propagation of Rhaponticoides mykalea (Hub.-Mor.) M. V. Agab. \& Greuter, a critically endangered endemic plant species.

To date there is no report on micropropagation of $R$. mykalea. This study is the first report on micropropagation of this species using seedlings from in vitro germinated embryos and aims to contrubute ongoing ex situ conservation programs. Additionally, this outlined protocol can be utilized as an aid in the local conservation programs to preserve this species, and it will lead for further studies on conservation and propagation of this rare and critically endangered endemic plant.

\section{Acknowledgements}

The authors are thankful to University of Adnan Menderes for financial support (Project no: FEF-07012)

\section{Author details}

Yelda Emek* and Bengi Erdag

*Address all correspondence to: yelda@adu.edu.tr

Department of Biology, Faculty of Arts \& Science, Adnan Menderes University, Aydın, Turkey

\section{References}

[1] Ekim, T, Koyuncu, M, Vural, M, Duman, H, Aytaç, Z, \& Adigüzel, N. Red Data Book of Turkish Plants (Pteridophyta and Spermatophyta). Ankara-Turkey: Turkish Association for the Conservation of Nature; (2000).

[2] Davis, P. H. Flora of Turkey and East Aegean Islands. Edinburg, U.K.: University Press; (1975).

[3] Hellwig, F. H. Centaureinae (Asteraceae) in the Mediterranean-history of ecogeographical radiation. Plant Systematics and Evolution (2004). , 246-137.

[4] Emek, Y, \& Erdag, B. Observations on Kuşadası Population of Rhaponticoides mykalea, Resarch Journal of Biology Sciences (2010). , 3(2), 169-174. 
[5] Fay, M. F. Conservation of Rare and Endangered Plants Using In Vitro Methods. In Vitro Cellular Development Biology (1992). , 28-1.

[6] Krogstrup, P, Baldursson, S, \& Norgaard, J. V. Ex Situ Genetic Conservation by Use of Tissue Culture. Opera Botany (1992). , 113-49.

[7] Fay, M. F. In What Situation Is In Vitro Culture Appropriate to Plant Conservation? Biodiversity Conservation (1994). , 3-176.

[8] Cuenca, S, Marco, J. B, \& Parra, R. Micropropagation From Inflorescense Stems of the Spanish Endemic Plant Centaurea paui Loscos ex Wilk. (Compositae). Plants Cell Reports (1999). , 18-674.

[9] Murch, S. J. KrishnaRaj S, Saxena PK. Phytomaceuticals: Mass Production, Standardization and Conservation. Scientific Review of Alternative Medicine (2000). , 4-39.

[10] Phillips, G. C, \& Hubstenberger, J. F. Micropropagation by Proliferation of Axillary Buds. In: Gamborg OL., Phillips GC. (ed) Plant Cell Tissue and Organ Culture. Fundemental Methods. Germany: Springer-Verlag Berlin-Heidelberg; (1995). , 46-54.

[11] Erdag, B, \& Emek, Y. In Vitro Micropropagation of Anthemis xylopoda O.Schwarz, a Critically Endangered Species from Turkey. Pakistan Journal of Biologicial Sciences (2005). , 8(5), 691-695.

[12] Cuenca, S, \& Marco, J. B. In Vitro Propagation of Centaurea spachii From Inflorescence Stems. Plant Growth Regulation (2000). , 30-99.

[13] Kurt, S, \& Erdag, B. In Vitro Germination and Axillary Shoot Propagation of Centaurea zeybekii. Biologia (2009). , 64(1), 97-101.

[14] Hammatt, N, \& Evans, P. K. The In Vitro Propagation of an Endangered Species: Centaurea junoniana Svent. (Compositae). The Journal of Horticultural Science and Biotechnology (1985). , 60-93.

[15] Hasançebi, S. Turgut Kara N, Çakır Ö,Arı Ş. Micropropagation and Root Culture of Turkish Endemic Astragalus chrysochlorus (Leguminosae). Turkish Journal of Botany (2011). , 35-203.

[16] Iriondo, J. M, \& Perez, C. Micropropagation and In Vitro Storage of Centaurium rigualii Esteve (Gentianaceae). Israel Journal of Plant Sciences (1996). , 44-115.

[17] Sha Valli Khan PSPrakash E, Rao KR. In Vitro Micropropagation of an Endemic Fruit Tree Syzygium alternifolium (Wight) walp. Plant Cell Reports (1997). , 16-325.

[18] Emek, Y, \& Erdag, B. Researchs on In Vitro Seed Germination of The Critically Endangered Endemic Plant Rhaponticoides mykalea (Hub.-Mor.) Journal of Nevsehir University of Science and Technology Institute (2012). , 2-46.

[19] Murashige, T, \& Skoog, F. A Revised Medium For Rapid Growth And Bioassays With Tobacco Tissue Cultures. Physiologia Plantarum (1962). , 15-473. 
[20] Miloševic, M, Vujakovic, M, \& Karagic, D. Vigour Tests as Indicators of Seed Viability. Genetika (2010). , 42(1), 103-118.

[21] Fowler, J, \& Cohen, L. Practical Statistics for Field Biology. Buckingham: Open University Press; (1990).

[22] Ruffoni, B, \& Massabo, F. Tissue Culture in Gerbera jamesonii hybrida. Acta Horticulturae (1991). , 289-147.

[23] Erdag, B, \& Emek, Y. Adventitious Shoot Regeneration and In Vitro Flowering of Anthemis xylopoda O. Schwarz, a Critically Endangered Turkish Endemic.Turkish Journal of Biology (2009). , 33(4), 319-326.

[24] Pevalek, K. B. In vitro germination of Centaurea ragusina L., a Croatian Endemic Species. Acta Biologica Cracoviensia Series Botanica (1998). , 40-21.

[25] Kurt, S. Researchs on In Vitro Seed Germination of The Centaurea zeybekii Wagenitz. PhD thesis. Adnan Menderes University Turkey; (2005).

[26] Dhar, U, \& Joshi, M. Efficient Plant Regeneration Protocol Through Callus for Saussurea obvallata (DC.) Edgew. (Asteraceae): Effect of Explant Type, Age and Plant Growth Regulators. Plant Cell Reports (2005). , 24-195. 
